\title{
Correction to: Cochlear Implant Made Easy by Bhopal Technique: Our Experience of 200 Patients
}

\author{
Satya Prakash Dubey ${ }^{1,2} \cdot$ Sanjay Agrawal $^{3}$ - Yamini Gupta ${ }^{4}$
}

Published online: 24 August 2019

(C) Association of Otolaryngologists of India 2019

\section{Correction to: Indian J Otolaryngol Head Neck Surg \\ (Apr-June 2019) 71(2):145-149 \\ https://doi.org/10.1007/s12070-019-01673-3}

In the original publication of the article, the corresponding author biography has been missed to publish. Now the same has been published in this correction.

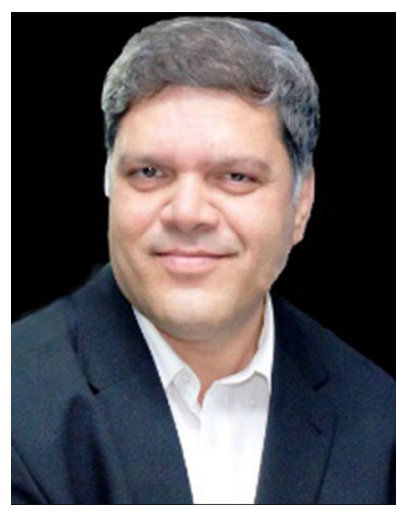

Dr. Satya Prakash Dubey currently Senior Consultant and Clinical Director of Divya Advanced ENT Clinic, Bhopal. Dr. Dubey received his M.S. degree from Gandhi Medical College, Bhopal, and then proceeded to Austria, Germany and Sydney for further training. Dr. Dubey has performed more than 800 cochlear implant surgeries in last 4 years, and he is a mentor surgeon for cochlear implant surgery in different parts of India. He was also a former editor of Indian Journal of Otolaryngology of India and presently president of AOI (The Association of Otolaryngologists of India). Apart from cochlear implant surgery, he has a special interest in nasoendoscopic surgeries and flexible endoscopy in ENT. He has also conducted several cochlear implant workshops to train ENT surgeons of the country Dr. Dubey won National I.S. Gupta Award from Rhinology Society of India in 2002 for paper titled 'Nasoendoscopic Pituitary Surgery Vs Conventional Approach'. He had presented a paper titled 'Flexible Endoscopy in ENT practice' at SAARC countries conference held at Delhi.

The original article can be found online at https://doi.org/10.1007/s12070-019-01673-3.

Satya Prakash Dubey

satyapdubey11@gmail.com

Yamini Gupta

dryamini10@gmail.com

1 The Association of Otolaryngologists of India, Kolkata, India

2 Divya Advanced ENT Clinic, Bhopal, M.P., India

3 Indore Endoscopy Centre, Indore, M.P., India

4 MGM Medical College, Indore, M.P., India 